\title{
Association analysis of g.68G $\rightarrow$ A SNP in CAPN1 gene with carcass and meat quality traits in goose raised in organic dehesa
}

\author{
Marina Solé $^{1}$, Sara Negro ${ }^{1}$, Alberto Membrillo ${ }^{2}$, Francisco Peña ${ }^{3}$, Valeriano Domenech ${ }^{3}$, \\ Juan Carlos Verona ${ }^{4}$, Maria Rubí ${ }^{4}$, Mercedes Valera ${ }^{1}$, and Antonio Molina ${ }^{2}$ \\ ${ }^{1}$ Departamento de Ciencias-Agroforestales, Universidad de Sevilla, Seville, 41013, Spain \\ ${ }^{2}$ Departamento de Genética, Universidad de Córdoba, Córdoba, 14071, Spain \\ ${ }^{3}$ Departamento de Producción Animal, Universidad de Córdoba, Córdoba, 14071, Spain \\ ${ }^{4}$ Inddeco S.L. Ganso Ibérico de Dehesa, Madrid, 28200, Spain \\ Correspondence to: Marina Solé (ge2sobem@uco.es)
}

Received: 2 May 2016 - Revised: 22 September 2016 - Accepted: 30 September 2016 - Published: 17 October 2016

\begin{abstract}
Meat quality is an important concern for the poultry industry. Domestic geese products obtained from free-range systems usually have rather tough meat, and it is necessary to select them to improve meat tenderness. The relation of the calpain 1 (CAPN1) gene with the post-mortem tenderness process of meat has been demonstrated in several species. Thus, the objective of the present study was to identify polymorphisms in this gene and to perform an association analysis between these polymorphisms and related economic traits in goose raised in the dehesa ecosystem. For the analysis, 50 geese of 3 different subpopulations (20 Embden Anser anser; 20 Toulouse Anser anser; $10 \mathrm{~F} 1$ cross) were studied. The experimental protocols were followed complying with principles of animal welfare. A novel SNP was found in the CAPN1 gene, g.68G $\rightarrow$ A. This polymorphism was statistically associated with different carcass and meat quality traits such as thigh muscle width $(P=0.020)$ and the $\mathrm{b}^{*} 10$-day meat colour parameter $(P=0.024)$ for the global goose population. The association of this gene with meat tenderness (Warner-Bratzler shear force) was confirmed in the case of female individuals of the Toulouse breed $(P=0.043)$. The results suggest the possibility of using molecular markers in CAPN1 gene as a potential tool for improving carcass and meat quality traits in goose breeding programmes.
\end{abstract}

\section{Introduction}

In the last few years there has been an increasing demand for the production of high-quality poultry meat, with the traditional products such as those obtained from free-range animals the most highly valued (Solé et al., 2016). Generally, geese are usually produced on specialized commercial farms, and although the meat from intensively raised stocks has a soft texture, it is considered by many traditional consumers to have less flavour (FAO, 2004). Thus, alternative rearing systems such as dehesa emerge as ecosystems of high ecological value for the extensive production of high-quality meat with outstanding and unique characteristics (Rey et al., 2006; Bouderoua et al., 2009; Keddam et al., 2010).
In the case of the geese industry, some commonly domestic breeds used for meat production are the Embden Anser anser and Toulouse Anser anser breeds. Males of the Embden are characterized by their ability to gain weight rapidly, and they are good foragers (Jacob and Pescatore, 2013), while females of the Toulouse breed are mainly used for egg and foie gras production (Batty, 1996). Over the last 50 years, there has also been a great advance in the development of hybrid breeds for intensive commercial poultry production (FAO, 2004), and the Embden and Toulouse breeds have been popular as stock for generating these hybrid crosses for meat production: for instance, the Embden $\times$ Toulouse cross offspring grow rapidly and have good fleshing qualities (Jacob and Pescatore, 2013). 
The genetic improvement of goose characteristics reared in free-range conditions using classical phenotype recording is extremely complicated. The application of genetic selection and the use of molecular technologies have played a key role in improving the productivity in animal breeding programmes. Advances in molecular genetics have led to the identification of genes or genetic markers controlling the variation in reproductive ability or productive characteristics (Kadarmideen, 2010). The micromolar calciumactivated neutral protease (CAPN1) gene encodes the $\mu$ calpain protease (Page et al., 2002), belonging to the enzymatic complex which degrades myofibrillar proteins during post-mortem tenderization and is responsible for meat tenderness (Avilés et al., 2009). Several SNPs in CAPN1 gene have been previously associated with tenderness in different livestock species (e.g. Cattle: Avilés et al., 2013; Casas et al., 2005; Costello et al., 2007 or Chickens: Felício et al., 2013; Shu et al., 2015; Zhang et al., 2008); however, it has not been previously described in Anser anser. Moreover, the genotype CC of c.2554T $\rightarrow$ C polymorphism of CAPN1 gene has been previously associated with an increase in live body weight (Felício et al., 2013) and the AA genotype of the $c .3535 \mathrm{G} \rightarrow$ A was associated with smaller WBSF values, lower water loss rates, and higher intramuscular force contents in chickens (Shu et al., 2015).

In a previous study, in the Embden, the Toulouse and its F1 cross goose breeds, less tenderness was observed in comparison with other specialized poultry meat species (Solé et al., 2016). In this case, a genetic selection of the animals together with the improvement of production systems and processing practices is recommended in order to improve meat tenderness.

Therefore, the main objective of this study was to identify polymorphisms in the CAPN1 gene in Anser anser and to perform an association analysis with carcass and meat quality traits in different goose breeds raised in organic dehesa.

\section{Material and methods}

\subsection{Animals and sampling}

For the molecular characterization of the goose population, a limited sample of 50 geese of 3 different genotypes or subpopulations (half in each sex type: 20 Embden Anser anser; 20 Toulouse Anser anser; 10 F1 cross) were analysed, derived from a previous study (Solé et al., 2016). All the animals were supplied by the companies Inddeco S.L. and Tierras de Ganso Ibérico S.L.

The following traits were evaluated: carcass characteristics (body weight, carcass weight, carcass length, carcass width, breast muscle weight, liver weight, thigh muscle width, thigh muscle length) and meat quality traits (Warner-Bratzler shear force; WBSF, $\mathrm{kg} \mathrm{cm}^{-2}$ ), cooking and drip loss, $\mathrm{pH}$ and colorimetric values of the breast muscle ( $L^{*}$, lightness, a measure of the light reflected $(100=$ white; $0=$ black $) ; a^{*}$, redness index, measures positive red and negative green; $b^{*}$, yellowness index, measures positive yellow, negative blue) measured $72 \mathrm{~h}, 5$ days and 10 days after slaughter. A detailed description of the methodology used can be found in Solé et al. (2016). The experimental protocols using meat geese in this study were followed complying with principles of animal welfare according to Spanish rules and regulations (EU Council Directive 86/609/EEC).

Genomic DNA was extracted from muscle tissue samples of the breast of the animals using standard laboratory protocols (Roche Diagnostics, $\mathrm{GmbH}$ ). The sequence of CAPN1 gene has not been previously described in the domestic goose (Anser anser). Thus, the primers for this gene fragment amplification (amplicon of $284 \mathrm{pb}$ ) were designed through the comparison of conservative regions of CAPN1 gene between Gallus gallus (NC_006090.3) and Peking duck Anas platyrhynchos (NW_004678518.1) GenBank sequences. The primers (F: 5'-CAGCTGCGGATCTTGTTC3', R: 5'-GCTGGTTTAAGCATTGAGCT-3') were designed using the software Oligo Primer Analysis System ${ }^{\circledR}$ (Molecular Biology Insights, Inc., USA). The PCR was performed using standard protocols in Eppendorf Thermal Cycler (Eppendorf ${ }^{\circledR}$, Germany). The thermal profiling consisted of a hot starting step at $94^{\circ} \mathrm{C}$ for $4 \mathrm{~min}$, followed by 35 cycles of $30 \mathrm{~s}$ at $95^{\circ} \mathrm{C}, 30 \mathrm{~s}$ at the annealing temperature of $58^{\circ} \mathrm{C}$, $4 \mathrm{~min}$ at $72^{\circ} \mathrm{C}$ and a final extension step of $10 \mathrm{~min}$ at $72^{\circ} \mathrm{C}$. The PCR products were analysed with Sequencher ${ }^{\mathrm{TM}}$ v.4.6 software.

\subsection{Statistical analysis}

Allelic and genotypic frequencies were performed in each goose subpopulation and in the global population. The Hardy-Weinberg equilibrium (HWE) was tested $(\alpha=0.05)$ with Genepop software (Version 3.4) (Rouseet, 2008). An association analysis of the detected SNP polymorphism was developed to determine marker effect with the different carcass and meat quality traits. For this purpose, the logistic regression procedure (Fagerland et al., 2008) was performed to determinate the association of each genotype (they were coded as 0,1 , and 2 for the number of risk alleles carried by individual subjects) in carcass and meat quality traits. To obtain the receiver operating characteristic (ROC) curve (Brethour, 2000) on a multi-marker basis, the values of the traits were transformed using two response levels, high (1) and low (0) values, according to their contribution to carcass and meat quality. This showed the predictive power of this molecular multi-marker tool through the percentage of area under the curve (AUC) in ROC space, equivalent to the probability that the classifier will rank a randomly chosen positive instance higher than a randomly chosen negative instance (Brethour, 2000). Sensitivity against 1 -specificity is plotted, with the area under the curve often being used as a measure of discriminatory performance ( 1 perfect prediction; 0.5 random guess). 
Table 1. Genotypic and allelic frequencies of polymorphism g.68G $\rightarrow$ A (CAPN1 gene) in the three goose subpopulations and in the global population.

\begin{tabular}{lllcc|lc}
\hline \multirow{2}{*}{ Breed } & Sex & \multicolumn{2}{c}{ Genotypic frequencies } & \multicolumn{2}{c}{ Allelic frequencies } \\
\cline { 3 - 7 } & & $\mathrm{f}(\mathrm{GG})$ & $\mathrm{f}(\mathrm{AG})$ & $\mathrm{f}(\mathrm{AA})$ & $\mathrm{f}(\mathrm{G})$ & $\mathrm{f}(\mathrm{A})$ \\
\hline \multirow{3}{*}{ Embden } & Male & 1.00 & 0.00 & 0.00 & 1.00 & 0.00 \\
& Female & 0.40 & 0.60 & 0.00 & 0.70 & 0.30 \\
& Overall & 0.70 & 0.30 & 0.00 & 0.85 & 0.15 \\
\hline \multirow{3}{*}{ F1 cross } & Male & 0.60 & 0.40 & 0.00 & 0.80 & 0.20 \\
& Female & 0.20 & 0.80 & 0.00 & 0.60 & 0.40 \\
& Overall & 0.40 & 0.60 & 0.00 & 0.70 & 0.30 \\
\hline \multirow{5}{*}{ Toulouse } & Male & 0.80 & 0.10 & 0.10 & 0.85 & 0.15 \\
& Female & 0.60 & 0.30 & 0.10 & 0.75 & 0.25 \\
& Overall & 0.70 & 0.20 & 0.10 & 0.80 & 0.20 \\
\hline \multirow{3}{*}{ Global } & Male & 0.84 & 0.12 & 0.04 & 0.90 & 0.10 \\
& Female & 0.44 & 0.52 & 0.04 & 0.70 & 0.30 \\
& Overall & 0.64 & 0.32 & 0.04 & 0.80 & 0.20 \\
\hline
\end{tabular}

Furthermore, when the association was statistically significant, the percentage of variance absorbed for the gene marker was measured for each goose sex type, subpopulation and in the global population using the general linear model (PROC GLM) and following the Gianola et al. (2009) methodology. The parameter SGoF+ (Carvajal-Rodriguez and Uña Álvarez, 2011) was used to control the false discovery rate (FDR) of the $p$ values at a significance level of $5 \%$ and a $\mathrm{q}(\mathrm{FDR})$ of $5 \%$. Statistical analysis was performed using SAS 9.2 (Statistical Analysis System, Inc., Cary, USA).

\section{Results and discussion}

In the present study, the sequences corresponding to the coding region of CAPN1 gene (GenBank KU363622, KU363624, KU363625) have been identified for the first time in the domestic goose (Anser anser). A novel SNP polymorphism in CAPN1 gene has been identified, named g. $68 \mathrm{G} \rightarrow$ A. The allelic and genotypic frequencies of this SNP in the three goose subpopulations (Embden Anser anser, F1 cross, Toulouse Anser anser) and for the global population were analysed (Table 1). All the frequencies conformed to HWE $(P=0.474)$. It was shown that the genotypes have a homogeneous distribution among parental subpopulations Embden and Toulouse, with the GG genotype predominant over others. The AA genotype has been identified only in the Toulouse breed ( 0.10 in both male and female individuals). The allelic frequencies showed that the $\mathrm{G}$ allele was the predominant one in all goose subpopulations.

The association between CAPN1 and meat tenderness (WBSF) has been previously described in several species such as poultry and cattle (Page et al., 2002; Mazzucco et al., 2010; Felício et al., 2013), but no significant association has been detected in the global goose population studied. The association analyses between g.68G $\rightarrow$ A SNP with carcass and meat quality traits using different fixed effects (breed, sex and genotype variables) are shown in Table 2. The association in the Embden male individuals could not be analysed because $100 \%$ of individuals presented GG genotypes. Regardless of the well-documented fact that the analysed CAPN1 gene is related mainly to the process of meat maturation in mammalian species, the existence of linkage disequilibrium with other carcass and meat characteristics in chickens cannot be excluded (Zhang et al., 2008; Felício et al., 2013). Thus, for the global goose population, a significant association was found between the CAPN1 SNP with the carcass characteristics of thigh muscle width $(P=0.0197)$ and the percentage of variance explained by the gene marker, $V_{a}$, was $10.97 \%$. According to the meat quality traits, the $b^{*} 10$-day parameter (meat colour, $P=0.024$; $\left.V_{a}=5.47 \%\right)$ was statistically significant. The ROC curves corresponding to statistically significant genetic association between the genotypes and these significant parameters are presented in Fig. S1a and S1b in the Supplement, respectively. The percentages of area under the curve in ROC space (prediction accuracy of the models with selected markers) referring to thigh muscle width and $\mathrm{b}^{*} 10$-day parameter (meat colour) were 0.54 and 0.60 , respectively. These values increased to 0.77 and 0.75 , respectively, when all the factors are included in the model for the global population.

Besides, a significant association has also been found with liver weigh $\left(P=0.045 ; V_{a}=4.16 \%\right)$, cooking loss $\left(P=0.006 ; \quad V_{a}=47.14 \%\right), \mathrm{pH}$ at 3 days $(P=0.008$; $\left.V_{a}=53.95 \%\right), \mathrm{pH}$ at 10 days $\left(P=0.008 ; V_{a}=44.10 \%\right)$ and $L^{*} 10$-day $\left(P=0.009 ; V_{a}=75.17 \%\right)$ parameters in the global Embden subpopulation. For the Embden female individuals, a significant association has been found with meat quality traits such as cooking loss $(P=0.038$; 
Table 2. Association analysis between g.68G $\rightarrow$ A (CAPN1 gene) with carcass characteristics and meat quality traits using a logistic regression procedure and general linear model in Toulouse and Embden subpopulations.

\begin{tabular}{|c|c|c|c|c|c|c|}
\hline \multirow{2}{*}{$P$ values } & \multirow{2}{*}{$\frac{\text { Global }}{\text { Genotype }}$} & \multicolumn{2}{|c|}{ Embden } & \multicolumn{3}{|c|}{ Toulouse } \\
\hline & & Global & Female* & Global & Male & Female \\
\hline \multicolumn{7}{|c|}{ Carcass characteristics } \\
\hline Carcass weight & 0.6020 & 0.1877 & 0.2386 & 0.1536 & 0.1002 & 0.6992 \\
\hline Carcass length & 0.4093 & 0.8193 & 0.8192 & 0.0568 & 0.0681 & 0.5045 \\
\hline Carcass width & 0.5641 & 0.4044 & 0.3873 & 0.0668 & 0.1335 & 0.3686 \\
\hline Breast muscle weight & 0.5409 & 0.3295 & 0.2216 & 0.1398 & 0.1919 & 0.3971 \\
\hline Liver weight & 0.5348 & $0.0449^{\mathrm{a}}$ & 0.4092 & 0.3842 & 0.5865 & 0.1792 \\
\hline Thigh muscle width & $0.0197^{a}$ & 0.7819 & 0.8104 & $0.0225^{\mathrm{a}}$ & 0.0537 & 0.2404 \\
\hline Thigh muscle length & $0.0256^{\mathrm{a}}$ & 0.7209 & 0.8091 & $0.0149^{\mathrm{a}}$ & 0.0635 & 0.1625 \\
\hline \multicolumn{7}{|c|}{ Meat quality } \\
\hline WBSF $\left(\mathrm{kg} \mathrm{cm}^{-2}\right)$ & 0.2578 & 1.0000 & 1.0000 & 0.1289 & 0.9414 & $0.0434^{\mathrm{a}}$ \\
\hline Cooking loss & 0.9065 & $0.0064^{b}$ & $\mathbf{0 . 0 3 8 3 ^ { \mathrm { a } }}$ & 0.1885 & 0.1587 & 0.9207 \\
\hline Drip loss & 0.3071 & 0.3442 & 0.4256 & 0.1118 & 0.2856 & 0.3615 \\
\hline $\mathrm{pH} 72 \mathrm{~h}$ & 0.5951 & $0.0077^{b}$ & 0.9959 & 0.2417 & 0.6353 & 0.3138 \\
\hline$L^{*} 72 \mathrm{~h}$ & 0.6477 & 0.3685 & 0.3718 & 0.4349 & 0.1892 & 0.8349 \\
\hline$a^{*} 72 \mathrm{~h}$ & 0.4709 & 0.2716 & 0.4845 & 0.9795 & 0.0537 & 0.1967 \\
\hline $\mathrm{b}^{*} 72 \mathrm{~h}$ & 0.4099 & 0.6091 & 0.6133 & 0.5827 & 0.8357 & 0.6774 \\
\hline pH 5 days & 0.4785 & $0.0115^{\mathrm{b}}$ & $0.0219^{a}$ & 0.1858 & 0.1457 & 0.7381 \\
\hline$L^{*} 5$ days & 0.8460 & 0.5798 & 0.3174 & 0.8088 & 0.4340 & 0.9363 \\
\hline $\mathrm{a}^{*} 5$ days & 0.6399 & 0.9848 & 1.0000 & 0.5770 & 0.5867 & 0.9353 \\
\hline$b^{*} 5$ days & 0.1910 & $0.0103^{b}$ & $0.0390^{\mathrm{a}}$ & 0.8230 & 0.7024 & 0.8194 \\
\hline pH 10 days & 0.4112 & $0.0078^{b}$ & 0.9959 & 0.8013 & 0.8357 & 0.6684 \\
\hline$L^{*} 10$ days & 0.1691 & $0.0089^{b}$ & 0.9959 & 0.4618 & 0.9441 & 0.1641 \\
\hline$a^{*} 10$ days & 0.7910 & 0.3212 & 0.3172 & 0.4627 & 0.9441 & 0.1205 \\
\hline$b^{*} 10$ days & $0.0242^{\mathrm{a}}$ & $0.0427^{\mathrm{a}}$ & $0.0383^{\mathrm{a}}$ & 0.5010 & 0.9294 & 0.3457 \\
\hline
\end{tabular}

* Association with male individuals could not be analysed for Embden breed. ${ }^{\mathrm{a}} P<0.05$. ${ }^{\mathrm{b}} P<0.01$. Bold values correspond to significant $p$ values after applying $\mathrm{SGoF}+$ correction for multiple testing.
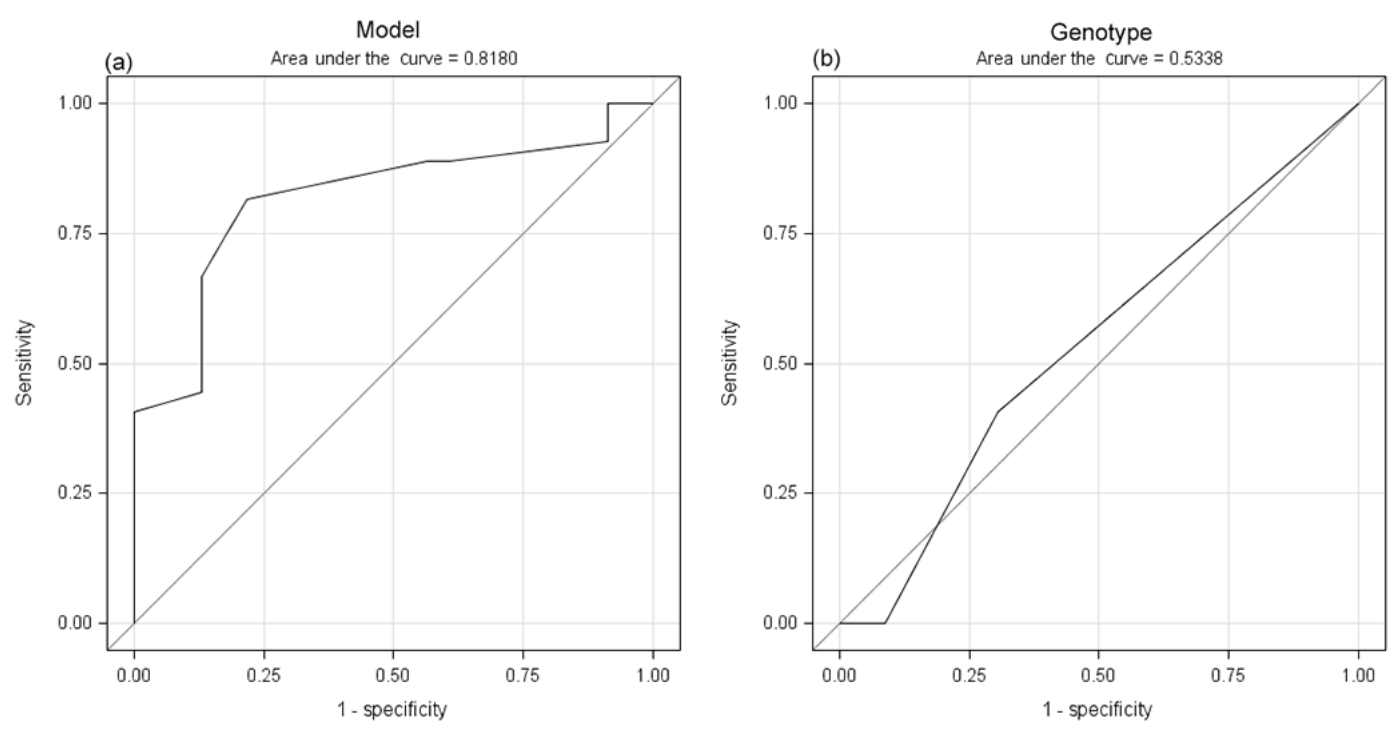

Figure 1. Receiver operating characteristic (ROC) curve analysis for the gene and the model predictive ability evaluation of meat tenderness (WBSF) in the global goose population. 
$\left.V_{a}=74.98 \%\right)$ and $\mathrm{pH}$ at 5 days $\left(P=0.022 ; V_{a}=60.48 \%\right)$. The Fig. S2 shows the ROC curves corresponding to the predictive level of the model and the significant parameters (cooking loss, 0.90 and $\mathrm{pH} 5$ days, 0.90 ), where the model shows a greater predictive ability. These findings suggested a biological implication of the CAPN1 gene in the metabolic pathway of post-mortem meat process in geese, as have been stated in other species before (Costello et al., 2007; Mazzucco et al., 2010; Shu et al., 2015).

However, a significant association has been found in the case of female individuals of the Toulouse subpopulation $\left(P=0.043 ; V_{a}=37.86 \%\right)$ for WBSF, as it has been previously mentioned that the females of this breed are mainly used for egg and foie gras production, therefore more selected for meat qualities than rate of growth (Jacob and Pescatore, 2013). The ROC curve analyses corresponding to the association between the genotype and WBSF in the global goose population and in the Embden and Toulouse subpopulations are shown in Figs. 1 and S3a-d, respectively. For the global goose population, the predictive power of the SNP marker is reduced (0.53), but the model including all the fixed effects (breed, sex, and genotype) shows high predictive ability (0.82). In the case of the Toulouse breed, the predictive power of the SNP (0.75) is higher compared to the Embden subpopulation (0.59). Finally, the complete model for the two subpopulations presents highly predictive ability (0.92 and 0.94, respectively).

\section{Conclusions}

This research describes for the first time part of the polymorphic coding region of CAPN1 gene in Anser anser and suggests that the novel g.68G $\rightarrow$ A SNP polymorphism of this gene is associated with some carcass and meat quality traits such as thigh muscle width and $b^{*} 10$-day (meat colour) parameters in the goose subpopulations raised in $d e$ hesa ecosystem. The association of this SNP marker with post-mortem meat quality traits suggests that this gene participates in the metabolic pathway in goose. This opens the opportunity for selection to improve meat tenderness in goose breeds. Due to the limitations of the sample size, it is therefore important to carry out future analyses into the association of these trait effects and CAPN1 gene in a larger animal sample to prove whether this association is maintained.

\section{The Supplement related to this article is available online at doi:10.5194/aab-2-423-2016-supplement.}

Competing interests. The authors declare that they have no conflict of interest.
Acknowledgements. The authors would like to thank Inddeco S.L. and Tierras de Ganso Ibérico S.L. for their contribution to this study.

Edited by: S. Maak

Reviewed by: two anonymous referees

\section{References}

Avilés, C., Azor, P.J., Pannier, L., Hamill, R. M., Membrillo, A., and Molina, A.: New single nucleotide polymorphisms in the mucalpain gene in Spanish maternal beef breeds, Anim. Biotechnol., 20, 161-164, 2009.

Avilés, C., Juárez, M., Peña, F., Domenech, V., Clemente, I., and Molina, A.: Association of single nucleotide polymorphisms in CAPN1 and CAST genes with beef tenderness from Spanish commercial feedlots, Czech J. Anim. Sci.. 58, 479-487, 2013.

Batty, J.: Domesticated ducks and geese, Beech House Publishing, Lancashire, UK, 1996.

Bouderoua, K., Mourot, J., and Selselet-Attou, G.: The Effect of Green Oak Acorn (Quercus ilex) Based Diet on Growth Performance and Meat Fatty Acid Composition of Broilers, Asian Austral. J. Anim., 22, 843-848, 2009.

Brethour, J. R.: Using receiver operating characteristic analysis to evaluate the accuracy in predicting future quality grade from ultrasound marbling estimates on beef calves, J. Anim. Sci., 78, 2263-2268, 2000.

Carvajal-Rodriguez, A. and de Uña-Alvarez, J.: Assessing significance in high-throughput experiments by sequential goodness of fit and q-value estimation, PLoS One, 6, 1-8, 2011.

Casas, E., White, S. N., Riley, D. G., Smith, T. P. L., Brenneman, R. A., Olson, T. A., Johnson, D. D., and Chase, C. C.: Assessment of single nucleotide polymorphisms in genes residing on chromosomes 14 and 29 for association with carcass composition traits in Bos indicus cattle, J. Anim. Sci., 83, 13-19, 2005.

Costello, S., O’Doherty E. O., Troy, D. J., Ernst, C. W., Kim, K.S., Stapelton, P., Sweeney, T., and Mullen, A. M.: Association of polymorphisms in the calpain I, calpain II and growth hormone genes with tenderness in bovine M. longissimus dorsi, Meat Sci., 75, 551-557, 2007.

Fagerland, M. W., Hosmer, D. W., and Bofin, A. M.: Multinomial goodness-of-fit tests for logistic regression models, Statist. Med., 27, 4238-4253, 2008.

FAO: Small-scale poultry production: technical guide, FAO Animal Production and Health Manual, Rome, Italy, 2004.

Felício, A. M., Boschiero, C., Balieiro, J. C. C., Ledur, M. C., Ferraz, J. B. S., Filho, T. M., Moura, A. S. A. M. T., and Coutinho, L. L.: Identification and association of polymorphisms in CAPN1 and CAPN3 candidate genes related to performance and meat quality traits in chickens, Genet. Mol. Res., 12, 472-482, 2013.

Gianola, D., de los Campos, G., Hill, W. G., Manfredi, E., and Fernando, R.: Additive genetic variability and the Bayesian alphabet, Genetics, 183, 347-363, 2009.

Jacob. J. and Pescatore, T.: Selecting Geese. Cooperative extension service University of Kentucky, College of agriculture, food and environment, Lexington, KY, USA, ASC-196, available at: http:// dept.ca.uky.edu/agc/pub_prefix.asp?Prefix01_ASC (last access: 23 March 2016), 2013. 
Kadarmideen, H. N.: The use of Genetic and Genomic Technologies to improve Reproductive Performance, in: Proceedings of the Australian College of Veterinary Scientists - Equine Chapter Conference, Gold Coast, Australia, July 2010, 36-44, 2010.

Keddam, R., Bouderoua, K., El-Affifi, M., and Selselet-Attou, G.: Growth performances, carcasses parameters and meat fatty acid composition of lamb fed green oak acorns (Quercus ilex) based diet, Afr. J. Biotechnol., 9, 4631-4637, 2010.

Mazzucco, J. P., Melucci, L. M., Villarreal, E. L., Mezzadra, C. A., Soria, L., Corva, P., Motter, M. M., Schor, A., and Miquel, M. C.: Effect of ageing and $\mu$-calpain markers on meat quality from Brangus steers finished on pasture, Meat Sci., 86, 878-882, 2010.

Page, B. T., Casas, E., Heaton, M. P., Cullen, N. G., Hyndman, D. L., Morris, C. A., Crawford, A. M., Wheeler, T. L., Koohmaraie, M., Keele, J. W., and Smith, T. P.: Evaluation of single-nucleotide polymorphisms in CAPN1 for association with meat tenderness in cattle, J. Anim. Sci., 80, 3077-3085, 2002.

Rey, A. I., Daza, A., López-Carrasco, C., and López-Bote, C. J.: Feeding Iberian pigs with acorns and grass in either free-range or confinement affects the carcass characteristics and fatty acids and tocopherols accumulation in Longissimus dorsi muscle and backfat, Meat Sci., 73, 66-74, 2006.
Rousset, F.: Genepop'007: a complete reimplementation of the Genepop software for Windows and Linux, Mol. Ecol. Resour., 8, 103-106, 2008.

Solé, M., Peña, F., Domenech, V., Clemente, I., Polvillo, O., Valera, M., Verona, J. C., Rubí, M., and Molina, A.: Carcass and meat quality traits in an Embden $\mathrm{x}$ Toulouse goose cross raised in organic dehesa, Asian Austral, J. Anim. Sci., 29, 838-844, 2016.

Shu, J. T., Zhang, M., Shan, Y. J., Xu, W. J., Chen, K. W., and Li, H. F.: Analysis of the genetic effects of CAPN1 gene polymorphisms on chicken meat tenderness, Genet. Mol. Res, 14, 13931403, 2015.

Zhang, Z. R., Liu, Y. P., Jiang, X., Du, H. R., and Zhu, Q.: Study on association of single nucleotide polymorphism of CAPN1 gene with muscle fibre and carcass traits in quality chicken populations, J. Anim. Breed. Genet., 125, 258-264, 2008. 